\title{
Anatomical Study on Hand Gworeum Skin in Human
}

\author{
Kyoung-Sik, Park
}

Dept. of Anatomy, College of Korean Medicine, Sangji University

\begin{abstract}
Objectives: This study was carried out to concrete the concept of Hand Gworeum Skin referred in Suwen of Huangdi Neijing.

Methods: The Hand Gworeum Meridian was labeled with latex in the body surface of the cadaver, subsequently dissecting a superficial fascia and muscular layer in order to observe internal structures.

Results: Skin histologically encompasses a common integument and a immediately below superficial fascia, this study established the skin boundary with adjacent structures such as relative muscle, tendon as its compass. The realm of the Hand Gworeum Skin is as follows: The skin close to the nipple on the 4th intercostal space, the interceps of biceps brachii muscle, the cubital surface at ulnad of bicipital aponeurosis, the anterior surface of the forearm, between flexor carpi radialis and palmaris longus(from wrist crease to 5chon above), the palm between the 3rd and 4th metacarpals on the cross part with the palm crease, the radiod from the middle finger nail(or the end of middle finger). The realm of the Hand Gworeum Skin is situated on between Hand Taeeum Skin and Hand Soeum Skin in front of arm.

Conclusion: The realm of Hand Gworeum Skin from the anatomical viewpoint seems to be the skin area outside the superficial fascia or the muscle involved in the pathway of the Hand Gworeum Meridian vessel, Collateral Meridian vessel, and Meridian muscle, being considered adjacent vessels or nerves at the same time.
\end{abstract}

$\overline{\text { Key Words }}$ : Hand Gworeum Skin, Meridian vessel, Meridian muscle, muscle, tendon

\section{Introduction}

Most oriental medical scholars have admitted a existence of 'Skin', since a concept of Skin is referred to 'Skin theory' chapter of Suwen, Huangdi Neijing. Huangdi Neijing says that Skin is spreading on a body surface as a portion of 12 Meridian vessels ${ }^{1)}$. And also Skin theory is applied to the field of plastic oriental medicine at present. But there is a few studies defining the properties of Skin, though more research is needed, if its clinical application is considered.
The recognized textbook ${ }^{2)}$ explains that according to Skin theory chapter of Suwen, Huangdi Neijing, Collateral meridian vessel of Meridian vessel belongs to Skin, and therefore Collateral meridian vessel is a component of Skin, Skin is that Meridian vessel is expressed on the surface of body. According to such opinion, it comes to a conclusion that Skin is devided into 12 Skins, as if Meridian vessel is devided into 12 Meridian vessels, that is, Skin is the skin realm of Meridian vessel.

The muscle connects the bone and the flesh,

\footnotetext{
- Received : 13 November 2020

- Revised : 1 December 2020

- Accepted : 2 December 2020

- Correspondence to : Kyoung-Sik, Park

Dept. of Anatomy, College of Korean Medicine, Sangji University, WonJu, Republic of Korea

Tel : +82-33-730-0667, Fax : +82-33-730-0667, Email : ksikpark@sangji.ac.kr

- This study was supported by Sangji University in 2019
} 
then the skin surrounds these corpuscle, Meridian vessel turns on Qi and Jing(Essence) between the muscle and the skin ${ }^{3)}$.

With relation to Meridian muscle, this is a linked concept to Meridian vessel, that is, Meridian muscle is the muscular system within the circulating boundary of Meridian vessel, therefore a name of 12 Meridian muscles is correspondent to that of 12 Meridian vessel ${ }^{4)}$. Though the concept of Meridian muscle is weighed the muscle or the flesh, the origin of Meridian muscle is same as that of Meridian vessel. Sangsun, Yang in 'Meridian muscle theory' chapter of taisuo argues that 12 Meridian vessels and 12 Meridian muscles are closely connected at an arm and a leg in three Yang or Ying forms ${ }^{2}$. This is thought to the same meaning as the record of Huangdi Neijing ${ }^{5)}$.

This study makes an attempt to set up the realm of Hand Gworeum Skin by reference to Meridian vessel, Meridian muscle, and especially Collateral Meridian vessel, in view of anatomic cadaver dissection on the ground of Skin theory chapter of Suwen.

\section{Materials and Methods}

\section{Preservative preparations and injection}

1) The preparation of a preservative phenol was dissolved in methyl alcohol at the rate of one to one $\mathrm{W} / \mathrm{V}(\mathrm{T}$ he 1st solution). Glycerin was dissolved in methyl alcohol at the rate of one to four $\mathrm{V} / \mathrm{V}$ and thereafter additional same amounts of glycerin was dissolved in this solution (the 2nd solution). The 1st and 2nd solutions were mixed well, and warmed $\left(30 \mathrm{~min}, 20{ }^{\circ} \mathrm{C}\right)$. Same amounts of methyl alcohol was added to this mixed solution and stirred for 10 minutes.
Finally additional 1.5 times of formalin was added to the mixed solution.

\section{2) Injectiontocadaver}

The sheath of the femoral artery \& vein was exposed by vertical incision at the medial third of the inguinal ligament, and the femoral artery was carefully separated from the femoral vein. A preservative was injected into the femoral artery at a speed of $150 \mathrm{ml}$ per minute. After $6 \mathrm{~L}$ of preservative was injected, the needle-inserted part was ligated, and subsequently an injector needle was inserted downwards for the preservation of the leg.

\section{Embalmment of Cadaver}

1) Cadaver was pending in the embalmment system for $40 \mathrm{hrs}$ at $40{ }^{\circ} \mathrm{C}$.

2) Cadaver was exposed for $1 \mathrm{hr}$ at room temperature, and after that, kept in refrigerated storage $\left(3{ }^{\circ} \mathrm{C}, 30 \%\right.$ humidity).

\section{Experimental procedure}

1) Hand Gworeum Meridian was labeled with latex in the body surface of the cadaver(Figure 1).

2) Meridian points were based on 'Korean Standard Acupuncture Point Location'6).

3) Pores were made by a drill in the vertical direction at each meridian point.

4) Skin and superficial fascia were dissected in order(Figure 2), investigating vessels and nerves and the exposed deep fascia thereafter labeled by latex, and then deep fascia was removed(Figure 3).

5) Subsequently we investigated vessels, nerves, muscles as factors of Meridian system, Meridian Muscles, Collateral Meridian ${ }^{7,8,9)}$ (Figure 4,5,6,7), 


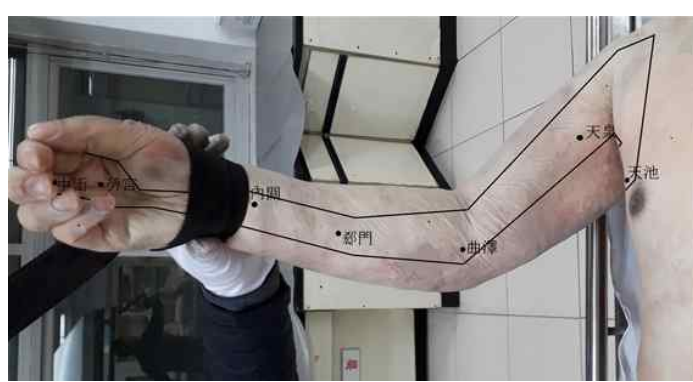

Fig. 1. Hand Gworeum Pericardium Meridian and the presumptive Hand Gworeum Skin realm.

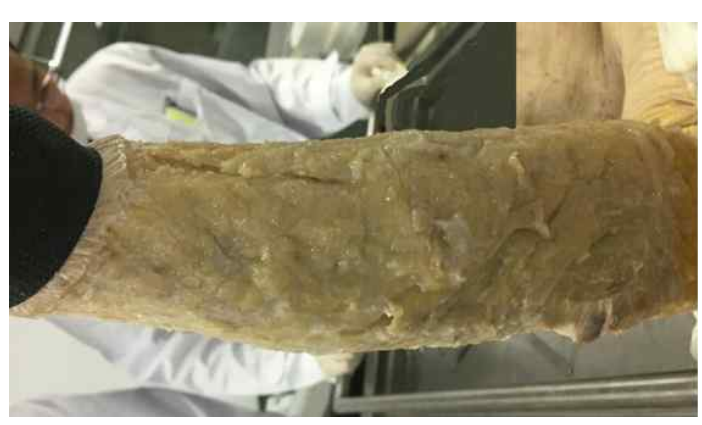

Fig. 2. The dissected superficial fascia.

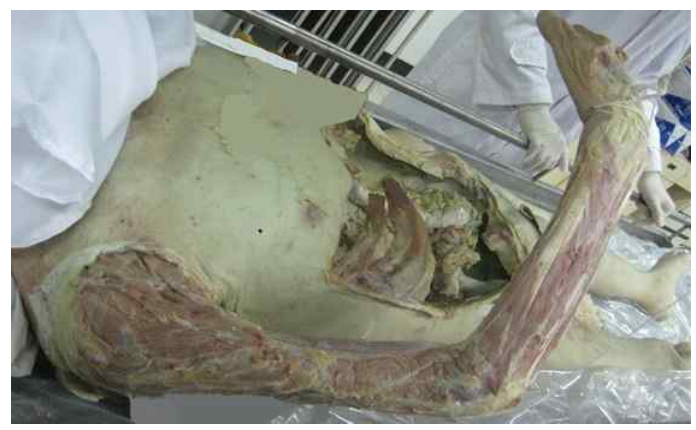

Fig. 3. The removed deep fascia.

in order to establish the realm of Hand Gworeum Skin.

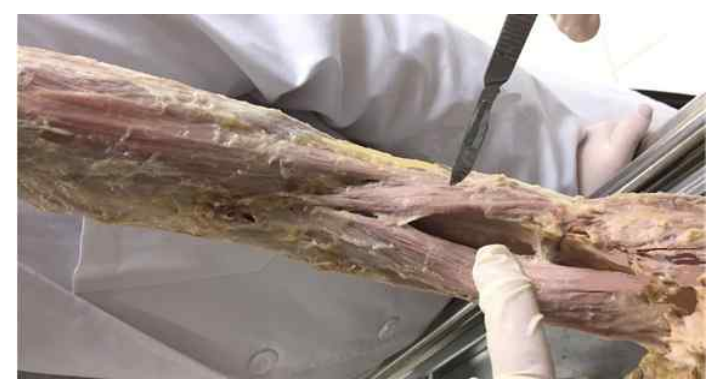

Fig. 4. Anterior muscle layer at the brachium.

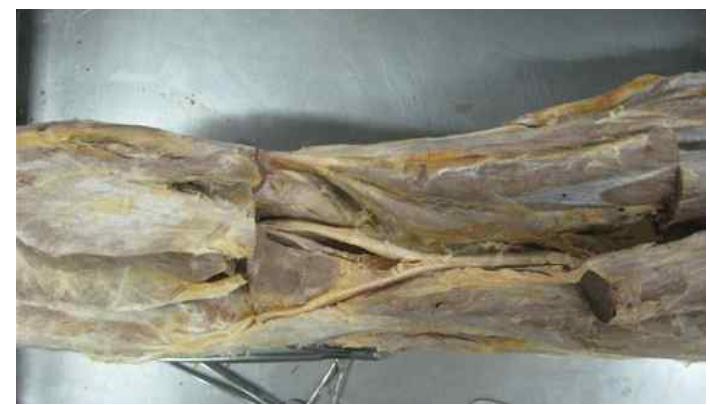

Fig. 5. Anterior muscle layer of elbow joint.

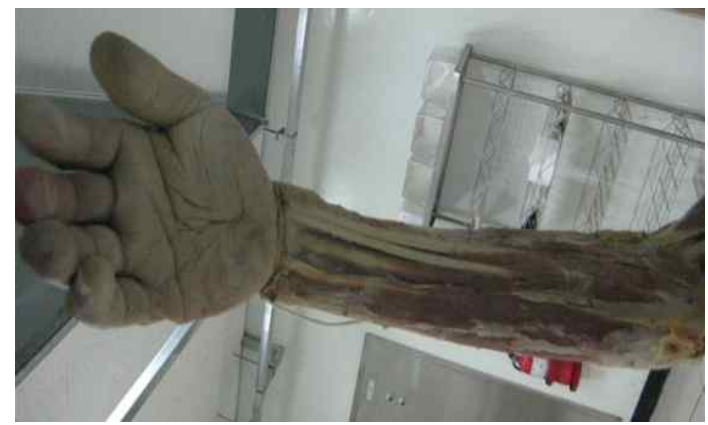

Fig. 6. Anterior muscle layer of antebrachium.

\section{Result}

Hand Gworeum Meridian seems to be situated in the depth level of superficial fascia from the viewpoint of human anatomy, but it is difficult 


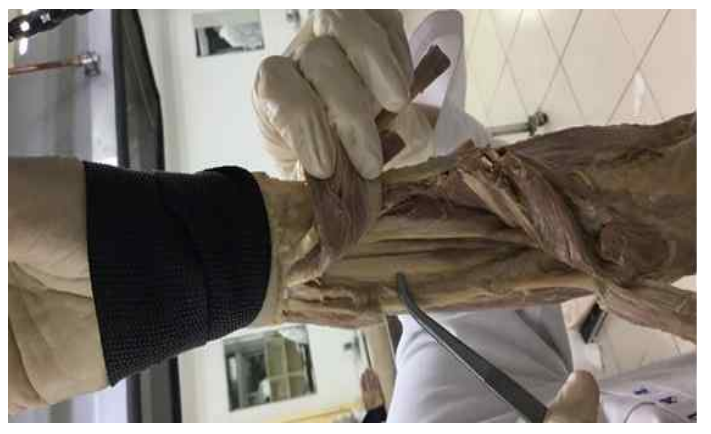

Fig. 7. Muscle layer of antebrachium in depth.

to define its depth concretely. This study defines Hand Gworeum Skin as boundary or realm with adjacent structures such as muscle, ligament, bone. From the anatomical view point, the skin areas assumed to define Hand Gworeum Skin are as follows(Figure 1, a solid line realm) :

The skin lateral to the nipple on the 4th intercostal space, the skin on the intercepts of biceps brachii muscle, the skin on the cubital surface at ulnad of bicipital aponeurosis, the skin on the anterior surface of the forearm, between flexor carpi radialis and palmaris longus, from wrist crease to 5chon above, the skin on the palm between the 3rd and 4th metacarpals on the cross part with the palm crease, the skin radiad from the middle finger nail(or the end of middle finger).

At the arm, Hand Gworeum Skin is located between Hand Taeum Skin and Hand Soeum Skin. At the forearm, Hand Gworeum Skin abuts on Hand Taeum Skin.

\section{Disscussion}

It is known that the distribution spread of 12 Skins and 12 Meridian muscles basically coincide with that of 12 Meridian vessels ${ }^{4}$. Collateral Meridian vessel is distributed at body surface, being seperated from Meridian vessel. This is thought to support the base of Skin, one Collateral Meridian vessel on body surface makes up one acupuncture point ${ }^{4,10)}$. This is thought to the same meaning as the record of Qisue theory and Qifu theory chapter of Suwen, Huangdi Neijing[10]. Hand Gworeum vessel is a Yin meridian with a descending flow of energy, running from Cheonji to Jungchung, Collateral Meridian vessel follows a path of Hand Gworeum vessel, since it split off from Naegwan of Hand Gworeum vessel.

Though Meridian muscle is a concept related to on the muscle or the flesh, Meridian muscle is related with Meridian vessel, since Meridian muscle is the muscular system of body surface within the circulating boundary of Meridian vessel. Huangdi Neijing assumes a name as Meridian vessel to link together the muscle and the vessel, Meridian vessel theory chapter of Lingshu, Huangdi Neijing says that the human brain and bone are basically produced from Gie(Energy) and Jing(Essence), then the muscle reinforces the bone, the flesh surrounds the bone, finally the skin surrounds the body surface, and herein Meridian vessel communicates with others 3,5). Hand Gworeum vessel origins from middle finger and goes through the ulnad of biceptical aponeurosis, the interceps of biceps brachii muscle, and the axillary fossa, then gets into the thorax via 4th $\mathrm{Rib}^{4,11}$.

Being based on this knowledge, we can deduce the substance of Hand Gworeum Skin, Hand Gworeum Skin is also guessed to be situated between Hand Taeeum and Hand Soeum Skin, this coincides with clinical situation. The 
illustration of Meridian explains that injury in the organ(Zangfu) is expressed on the skin, Xieqi(Evil) invades the organ through Meridian vessel, according to 5 Colors theory chapter of Lingshu, the skin color reflects internal disease, so 12 Skins can be also applied to the treatment or diagnosis of internal disease[10]. Acupuncture \& Moxibustion(Zhenjiuxue) explains that according to Meridian vessel theory chapter of Lingshu, the treatment of shidong-shosheng disease begin with 'Skin' concept, so if Xieqi(Evil) invades internally, the sweating therapy and drug taking method are used together ${ }^{4)}$.

\section{Conclusion}

This study was carried out to define Hand Gworeum Skin in human, dissecting and splitting a body among superficial fascia and muscular layer in order to expose inner structures such as muscles, nerves, and blood vessels thought to be related to Hand Gworeum Skin. We obtained the conclusions as follows:

1. The realm of Hand Gworeum Skin in human seems to be closely matched to Meridian vessel, Collateral meridian vessel, Meridian muscle as a part of the meridian system. To put it more concretely, including the skin laterally close to the nipple on the $4_{\text {th }}$ intercostal space, the interceps of biceps brachii muscle, the cubital surface at ulnad of bicipital aponeurosis, the anterior surface of the forearm, between flexor carpi radialis and palmaris longus(from wrist crease to 5chon above), the palm between the 3rd and 4th metacarpals on the cross part with the palm crease, the radiad from the middle finger nail(or the end of middle finger).
2. The realm of Hand Gworeum Skin at the brachium region is discerned from Hand Taeum Skin and Hand Soeum Skin.

3. From the viewpoint of human anatomy, Hand Gworeum Skin appears to be made up of the common integument, superficial fascia histologically, including the relevant nerves or blood vessels.

\section{References}

1. Bae BC. Suwen of HUANGDI NEIJING: The Book Translated into Korean. Seoul: Korea Bio Medical Science Institute. 2000. p.248-251.

2. The Editorial Alliance of Meridian and Acupoint, Korean Medicine. Meridian and Acupoint. Medical Book Jung Dam. 2019. p.261, 292-294.

3. S JG. The Interpretation of Suwen, Huangdi Neijing. Eui Sung Dang Publishing Co. 2010. p.81-82.

4. The Editorial Alliance of Acupuncture \& Moxibustion, Korean Medicine. Acupuncture \& Moxibustion(Zhenjiuxue). 3rd ed. Volume I. Seoul: Gypmundang. Co. 1991. p.45-47, 64, 147-149, 155, 171-174, 565-579.

5. Kim SH. Lingshu of HUANGDI NEIJING. Jumin Publishing Co. 2003. p.135-136.

6. Korean Society of Meridian \& Acupoint, Korean Acupuncture \& Moxibustion Society, Institute of Korean Medicine. Editing commissioners involving Shon IC. Korean Standard Acupuncture Point Location. 2006. p.1-4, 30 .

7. Netter FH. Atlas of Human Anatomy: The CIBA COLLECTION(ESSENTIALS). Japan: Daiichi Seihan. 1989. Plate 168, 174, 448, 
451-456.

8. Putz R, Pabst R. Atlas of human anatomy: SOBOTTA. Volume 1, 2. Munchen: Fisher Verlag Inc. 2000. Vol.1. p.186, 194, 201, Vol.2. p.56, 58

9. Telger TC. Photographic Atlas of Practical Anatomy: WALTER THIEL. Volume I, II. New York: Springer-Verlag Inc. 1999. Vol.II. p.156-193, 323-337.

10. Shon IC, Lee MH. The illustration of Meridian(by Yungui, Lin): The piece translated into Korean. Seoul: Cheong Hong Publications Ins. 2007. p.306, 324.

11. Ahan YK. A Collection of Meridian Acupoint. Seoul: Sungbosa Publishing Co. 1991. p.478-496.

\section{ORCID}

Bak kyung sik https://orcid.org/0000-0002-2152-5127 